This is the peer reviewed version of the following article: Pallotti, F., Tubaro, P. and Lomi, A.

(2015), How Far do Network Effects Spill Over? Evidence from an Empirical Study of Performance Differentials in Interorganizational Networks. European Management Review. doi:

10.1111/emre.12052, which has been published in final form at

http://dx.doi.org/10.1111/emre.12052. This article may be used for non-commercial purposes in accordance with Wiley Terms and Conditions for Self-Archiving.

Accepted 20 July14, available online 14 September 2015

Citation: Pallotti, F., Tubaro, P. and Lomi, A. (2015), How Far do Network Effects Spill Over? Evidence from an Empirical Study of Performance Differentials in Interorganizational Networks. European Management Review. doi: 10.1111/emre.12052 


\title{
How far do network effects spill over? Evidence from an empirical study of performance differentials in interorganizational networks
}

\begin{abstract}
Organizations join interorganizational networks in the hope of gaining exposure to learning opportunities, and accessing valuable extramural resources and knowledge. In this paper we argue that participation in interorganizational networks also reduces performance differentials among organizational nodes. We examine three alternative mechanisms capable of sustaining this prediction. The first (strength of ties) operates at a strictly local level defined in terms of dyadic relations linking organizations. The second mechanism (social proximity) operates at an intermediate - or meso level of interdependence defined in terms of membership in overlapping cliques into which interorganizational networks are typically organized. The third mechanism (structural equivalence) is global and pertains to jointly occupied network positions. The objective of this paper is to examine at which of these levels network effects operate to reduce performance differentials among members of interorganizational networks. Our empirical analysis of performance differentials between hospitals in a regional community supports the following conclusions: (i) performance spillover effects are highly differentiated and vary significantly across network levels; (ii) organizations occupying similar positions within the network are more similar in terms of performance; (iii) joint membership in multiple sub-groups (or cliques) reduces performance differentials up to a limit; after this limit is reached, the performance of organizational partners begins to diverge; (iv) the strength of direct collaboration between organizational partners does not necessarily reduce interorganizational performance differentials. The results of the study are new because available research on interorganizational networks says little about the range of network effects - i.e., about how far the performance spillover effects that operate through networks propagate throughout organizational fields and communities. These results are also consequential because they suggest that network effects on performance differentials are sensitive to the specification of network boundaries.
\end{abstract}

\section{Keywords}

Cliques, Interorganizational networks, Performance differentials, Social influence, Structural equivalence. 


\section{INTRODUCTION}

Students of organizations and management demonstrate an increased interest in the role of interorganizational relations as joint problem solving arrangements established by interdependent organizations to support, control, and coordinate flows of material and symbolic resources (Cropper et al., 2008). The basic argument behind this interest is that connected organizations are better able to manage the uncertainty inherent in their mutual dependencies, recognize and access key resources across corporate boundaries, and learn from each other by sharing and transferring relevant knowledge and information (Powell et al., 1996). Interorganizational networks provide access to the competitive and operational experience of others resulting in best practices that can then be more easily understood, evaluated and, possibly, assimilated (Ingram and Baum, 1997).

Examples of research building on this perspective include studies of strategic alliances (Gulati and Gargiulo, 1999; Stuart, 2000), collaborative manufacturing (Helper et al., 2000), interlocking directorates (Haunschild, and Beckman, 1998; Haunschild, 1994), joint ventures (Polidoro, Ahuja and Mitchell, 2011), and models specifying organizational outcomes as a function of the quality, status, and prestige of network associates (Baum and Oliver, 1991; Stuart, Hoang and Hybles, 1999).

In all these examples of interorganizational networks, organizations are assumed to establish collaborative agreements in the hope to learn and benefit from the experience, resources, and capabilities of network partners (Powell et al., 1996). Establishing collaborative relations is attractive precisely because network ties may: "Provide unique opportunities to learn from peer firms, and (have) a distinctive capacity to motivate members to strive for higher performance" (Sgourev and Zuckerman, 2011: 13). Thus, organizations establish collaborative relations under expectations that assimilation of extramural resources, competencies and skills that network ties afford will eventually yield higher levels of individual performance (Cohen and Levinthal, 1990). However, if this expectation is generally satisfied, then the aggregate outcome is that performance 
differentials between connected organizations will decrease as a direct consequence of the reduced diversity in the set of organizational capabilities and skills present in the network (Han, 1994).

In this paper, we seek to clarify how - and to what extent - this assimilation process sustained by network ties affects performance differentials among participants in interorganizational networks. Our work extends prior research in two ways. First, we show that network effects on interorganizational performance differentials operate differently across structural levels. With few exceptions (Provan and Sebastian, 1998), available research has been conducted at one single level of analysis (Provan, Fish and Sydow, 2007). We estimate models that specify how the strength of direct partnership (social interaction), co-membership in cliques (social proximity), and shared network position (structural equivalence) affect interorganizational differences in performance. The underlying idea guiding our analysis is that if interorganizational relations have implications for organizational performance, they should be revealed by variations in performance differentials between connected organizations. Because networks are multi-level constructions, this objective involves identifying the mechanisms that bound performance assimilation effects across network levels. How far do network effect on performance spill over? We know that networks influence behavior. We simply do not know the range of such influence which may vary from the very local (individual network ties) to the global (network positions, or roles). To the best of our knowledge no research is available that has addressed this question directly in the context of organizational fields and communities.

Second, while most prior research has focused on "network effects" on individual performance, our interest in this paper is on differences in performance between connected organizations - with unconnected organizations used as case controls. This stance is consistent with our objective of establishing the level at which network relations affect interorganizational performance differentials. Are organizations connected by network ties more similar in terms of performance than organizations that are not connected? And if this is the case, at what level are these differences more clearly observable? With the partial exception of Mizruchi and Marquis 
(2006) we are not aware of research that has attempted to address these questions directly despite the clear tendency during the last decade or so to study networks at the level of dyads (Stuart, 1998; Rivera, Soderstrom, and Uzzi, 2010). The analysis we present provides unambiguous answers to these questions while allowing for the possibility that interorganizational performance differentials - which are necessarily dyadic - may not be best explained at the dyadic level.

We situate our study in the context of original fieldwork and data that we have collected on an interorganizational regional community of hospital organizations. Interorganizational networks are particularly relevant for understanding organizational outcomes in the health care industry where: "Many organizations in a community may well be considered part of a broadly defined delivery system and connected to one another in a variety of ways" (Provan and Sebastian (1998: 454). More specifically, our analysis focuses on the network of patient transfer relations between hospitals. We focus on this specific and well-studied interorganizational relation because prior literature has demonstrated that patient transfers represent an important occasion for reciprocal learning as they imply collaboration, knowledge transfer and information sharing between partner hospitals involved in the transfer (Iwashyna, 2012; Lee et al., 2011).

In our study, the relational content is unambiguously specified and the strength of the relation accurately measured. Patient transfer between hospitals would not be possible without a considerable investments and explicit arrangements in support of joint decision making (Lomi et al. 2014). As we explain later in the paper, patient flows represent the physical traces of complex arrangements established to support and facilitate interorganizational collaboration and joint decision making. For this reason patient flows represent a signal of an underlying collaboration and knowledge sharing between partner hospitals. Inter-organizational knowledge sharing is particularly important for organizations in fields where the knowledge base is complex and expanding (Powell et al., 1996; Uzzi, 1997) - such as healthcare.

\section{THEORETICAL BACKGROUND AND HYPOTHESES}




\subsection{Theoretical background}

According to Ansell (2008: 75): "A network can be thought of as an institution to the extent that it represents a stable or recurrent pattern of behavioral interaction or exchange be tween individuals or organizations." As such, networks play a role that is in many ways similar to that of the powerful collective actors that institutional theories have long identified as the main generators of isomorphic pressures within organizational fields (DiMaggio and Powell, 1983; Galaskiewicz, 1985).

We know, for example, that organizations connected by network ties are more likely to imitate network partners, assimilate their knowledge, and become progressively more similar along a number of meaningful dimensions (Galaskiewicz and Burt, 1991; Galaskiewicz and Wasserman, 1989; Greve, 1996; Rao et al., 2000). This happens because networks speed up the diffusion of practices, and make available salient information about the costs and potential benefits of adoption decisions (Davis and Greve, 1997; McDonalds and Westphal, 2003; Westphal and Zajac, 1997). As these and innumerable other studies demonstrate, membership in networks exposes organizational nodes to considerable mimetic pressures - pressures to imitate, assimilate or emulate the behavior of partners. Interorganizational networks clearly represent: "A context in which individual efforts to deal rationally with uncertainty and constraint often lead, in the aggregate, to homogeneity in structure, culture, and output" (DiMaggio and Powell 1983:147).

Considered as institutions, however, interorganizational networks present a number of distinctive features that require a more detailed organizational analysis. Two such features are directly relevant to our current purposes. The first is that mimetic pressures prevail on normative and coercive pressures (DiMaggio and Powell, 1983). This is the case because interorganizational networks are based on the formation of decentralized cooperative relations between organizations that otherwise retain autonomy and control over their own resources (Ebers, 1997). Network nodes do not substitute market transactions with hierarchical relations (Williamson, 1991), but continue to operate as independent organizations (Powell, 1990). In interorganizational networks problems of 
interdependence are solved by relational coordination - a "communication - and relationshipintensive form of coordination" (Gittell, 2002: 1408) involving the creation and management of enduring network ties. Consequently, isomorphic pressures come from the accumulation of decentralized dyadic relations with partner organizations, rather than from the adherence to ge neral institutionalized norms promulgated by the state and promoted by the professions.

The second distinctive feature of what has been called "network institutionalism" (Ansell, 2008) is that the internal structure of interorganizational networks is highly differentiated: Not all members of interorganizational networks have relations with all others, and relations tend to be highly clustered around a limited number of nodes. As a consequence, the overall network density tends to be low and members vary considerably in centrality and connectivity within the network (Baum, Shipilov and Rowley, 2003). The main implication of internal differentiation is that isomorphic pressures are distributed unevenly across networks. Membership in networks does not guarantee global homogeneity in structures or behavior of members. We know that individual organizations become “'relationally' and 'positionally' embedded in interfirm networks that affect their behavior and performance" (Rowley et al., 2004: 467). Hence, the strength of mimetic pressures depends on elements of embeddedness such as: (i) the specific relations that organizations develop; (ii) the network sub-groups (cliques) they join, and (iii) the positions that they come to occupy within the overall network structure (Zaheer and Bell, 2005).

In summary, studies of network institutionalism (Ansell, 2008) emphasize network relations as: "channels that diffusely and imperfectly direct transfers between nodes, facilitating information spillovers (and other externalities)" (Owen-Smith and Powell, 2004: 5. Emphasis added). What these studies are yet to clarify are the mechanisms that sustain the spillover effects responsible for the reduction of organizational differences in "structure, culture, and output" (DiMaggio and Powell 1983). This is necessary precisely because network affiliation is an outcome of individual partner selection decisions - and not of normative or coercive pressures. Consequently, questions remain open about the forces that bound spillover effects in organizational communities and fields, 
and about the level at which network effects effectively operate. In the next section we make a first step in the direction of filling this gap.

\subsection{Hypotheses}

As we have discussed in the prior section, theory and available empirical studies recognize that the presence of network relations are systematically associated with tendencies toward mimetic isomorphism (DiMaggio, 1986). In this study we are interested in analyzing the range of network effects on organizational performance, i.e, in determining how far network effects spill out. We address this issue by examining the factors that affect interorganizational performance differentials. The conventional explanation is that connected organizations tend to become more similar to their partners because direct contact in the form of dyadic relations increases mutual awareness, facilitates the transfer of knowledge across organizational boundaries, and accelerates the diffusion of organizational practices (Larson, 1992). Alternatively, connected organizations may become more similar to their partners because they share membership in the same network clusters - or cliques (Rowley et al., 2004). Finally, organizations may become more similar to their partners because they face similar opportunities and constraints, i.e., because they occupy similar network positions (DiMaggio, 1986). Each of these explanations implies a different range for network effects: very local in the first case (direct contact) and global in the third case (structural equivalence), with cliques representing an intermediate range of influence. We discuss these possibilities in turn (Mizruchi and Marquis, 2006).

Available studies in support of the direct contact perspective sustain the argument that direct social interaction makes network partners more similar, as "firms would look to their peers with whom they shared social ties and would be influenced by their behavior" (Mizruchi and Marquis, 2006: 190). Network ties transmit information, diffuse knowledge, and transfer material resources that are likely to influence individual behavior in the direction of making partners more homogeneous in terms of structures, behavioral orientation and, arguably, performance (Beckman 
and Haunschild, 2002; Ahuja, 2000; Davis and Greve, 1997; Hedstrom, Sandell, and Stern, 2000). The exchange of high-quality information and fine-grained knowledge depends on the strength of interpersonal relationships between a knowledge source and a potential recipient (Larson, 1992; Szulanski, 1996; Uzzi, 1996). According to this perspective, we should expect to observe smaller performance differentials at a local, micro level of analysis (Mizruchi and Marquis, 2006). This view is summarized in the following hypothesis 1 :

(H1) Stronger direct relations between organizations will be associated with smaller differences in their performance.

This prediction is fully aligned with results of empirical studies showing that the strength of ties linking two organizations encourages communication, facilitates information sharing and promotes "social learning of adaptive responses, rather than other, less productive, forms of interorganizational imitation.” Kraatz (1998: 621). Available research, however, has not considered how these potentially beneficial effects may be associated with a decreased difference in the performance of connected organizations.

The strength of direct relations between partner organizations is important, but it is by no means the only potential source of influence that interorganizational networks exercise on organizational behavior and performance. Considerably less understood and investigated is the effect of intermediate network substructures on organizational performance - i.e., the effect of membership in "networks within networks", or cliques (Provan and Sebastian, 1998). Cliques may be viewed as relatively stable groups of organizations that are more densely interconnected to one another than to other organizations in the network (Wasserman and Faust, 1994).

Membership in cliques is rarely unique because interorganizational networks are typically not decomposable systems (Simon, 1962). Consequently, organizations tend to be members of multiple cliques - an empirical regularity that has been frequently linked to the "small world" 
character of interorganizational networks (Baum, Shipilov and Rowley, 2003). Dually, cliques overlap - or "intersect" - to the extent that they are linked by common members (Blau and Schwartz, 1997 [1984]; Breiger, 1974). The main prediction in this case is that organizations may perform similarly to the extent that they belong to overlapping cliques because: "the outcomes for firms are fundamentally intertwined with those of other firms that belong to the same clique" (Rowley et al., 2004: 454). Dense interconnections between members of the same cliques facilitate the establishment of cooperative norms and the adoption of similar behaviors that come from sampling the experience from common exchange partners (Rowley et al., 2005). Because cliques are generated by network ties, organizations being members of a clique or sharing membership in different cliques rely on a strong element of cohesion that enhances organizational learning, reciprocal awareness, and knowledge sharing. This, in turn, is likely to lead organizations to adopt similar behaviors and attain similar levels of performance (Rowley et al., 2004). Along these lines, clique co-membership can be interpreted as an indicator of social proximity determined by membership in intersecting social circles defined around individual organizations (Alba and Kadushin, 1976).

This view is justified also on more general theoretical grounds. According to Blau and Schwartz, for example (1997[1984]:1): "Individuals are located at the intersection of numerous social circles, so that the ingroup members along one dimension are not the same as their ingroup partners along other dimensions." As the intersection (overlap) between social circles (cliques) increases, the various "ingroup partners" will tend to converge to a unique set. Hence, the social proximity between organizations also increases due to the fact that organizations find themselves increasingly connected to the same alters which they repeatedly encounter in different settings. For this reason we expect mimetic forces to operate at the meso level of the "networks within networks" defined by membership in multiple cliques (Provan and Sebastian, 1998). According to this second perspective, we should expect to observe smaller performance differentials between 
organizations sharing membership in multiple cliques. This view is summarized in the following hypothesis 2 :

(H2) Higher degrees of clique overlap between organizations - i.e., stronger levels of social proximity - will be associated with smaller differences in their performance.

This prediction seems to be justified also in light of studies on how the performance-enhancing effects of interorganizational networks depend on integration within multiple small groups of interacting partners (Provan and Sebastian, 1998). As it is common, extant research focuses on the effects of network integration on individual organizations. But it is precisely this integration that is behind the reduction in performance differentials that we predict to be associated with joint membership in multiple cliques.

According to a third theoretical vision, network positions that organizations come to occupy - rather than direct social interaction or social proximity - are the main source of variation in opportunities and constraints and hence in performance (Burt, 1982). This vision is based on the notion of structural equivalence, or similarity in network positions that organizations come to occupy by virtue of similarity in their patterns of relation with third parties (Lorraine and White, 1971).

Structurally equivalent organizations depend on the same resources (or resources controlled by the same alters) and are, therefore, more likely to compete (Burt, 1987; Mizruchi, 1993). Competition induced by structural equivalence may also lead to similarity in behavior and performance because competitors are likely to emulate the actions of successful others perceived to be in a similar position with respect to fundamental resource dependencies (Hallen, 2008; Zaheer and Bell, 2005).

One possible consequence of structural equivalence is that organizations jointly occupying a similar network position - in the limit, the same network position - will face similar constraints and 
opportunities, and will be therefore more likely to attain similar levels of performance. According to this view, we should expect to observe smaller performance differentials between organizations that do not necessarily interact with each other, but that instead share the same position within the global network. Burt and Talmud (1993) define organizational niches - or subsets of organizations that "share the same fate" (Hannan and Freeman, 1989) - as sets of structurally equivalent organizations. According to DiMaggio's influential statement, (1986: 345. Emphasis ours): "Structural equivalence analysis is akin to (and in fact theoretically derived from) role theory: Its premise is that organizations with similar patterns of relations to other organizations will become more similar even if they do not interact with one another directly." This view provides the theoretical foundation for our prediction of similarity in organizational performance among structurally equivalent organizations summarized in the following hypothesis:

(H3) The more similar are the network positions that two organizations occupy, the smaller will be their difference in performance.

Our third prediction is consistent with the results of extensive research showing that organizations occupying similar network positions (i.e., structurally equivalent organizations) enjoy and face similar opportunities, benefits and constraints (DiMaggio, 1986; Gulati and Gargiulo, 1999; Burt, 1982; Burt and Talmud, 1993). As a consequence, performance is unlikely to vary widely between organizations with similar "positional embeddedness" profiles. In other words, hypothesis three predicts that performance is more likely to vary between rather than within network positions (Powell, Koput and Smith-Doerr, 1999).

Our discussion so far focused on interorganizational performance differentials - a naturally dyadic concept. This is consistent with the widely held view that the conditions for learning and assimilation tend to operate at the level of dyadic relations between organizations (Gulati, 1995; Podolny, 1994; Rivera, Sodestrom, and Uzzi; 2010 Stuart, 1998) and that firm-level models are 
inadequate to capture network-based processes because they do not take into account the identities of the partners (Stuart, 1988). Unlike the extensive literature based on dyadic models, the last two hypotheses suggest that dyadic variation may be explained by factors defined at different (higher) levels of analysis. Many of the empirical studies currently available focus only on one level of analysis while ignoring effects potentially operating at different levels (Galaskiewicz and Burt, 1991; Rowley et al., 2004; Hallen, 2008). With few notable exceptions (Burt, 1987; Ferlie et al., 2005; Mizruchi and Marquis, 2006), studies have not simultaneously considered the influence effect of micro, meso, and macro levels of analysis on performance differentials between organizations. This is what we do in the empirical part of the paper by examining how interorganizational peer effects defined at the strictly local, intermediate and global network levels affect performance differentials among members of interorganizational networks.

\section{RESEARCH DESIGN AND MODELS}

\subsection{Empirical Setting and Sample}

The opportunity to put our general arguments in empirical context is provided by data that we have collected on a community of hospital organizations providing health care coverage to Lazio - one of the largest Italian regions with a population of approximately 5,700,000 inhabitants. Hospital organizations provide an almost ideal empirical setting for studying processes of mimetic isomorphism because - as Fennell (1980: 505) put it: "Hospitals (...) will be defined as fit only if they can offer everything other hospitals in the area offer" (Also cited in DiMaggio and Powell, 1983: 154). This known tendency of hospitals (as highly institutionalized professional organizations) toward mimetic isomorphism is strengthened when through patient transfer relations hospitals have a direct opportunity to learn the organizational and clinical practices enacted by partners. We focus on patient transfer because research has shown that this specific relation cannot exist without intense mutual communication and sharing of information on internal clinical practices (Iwashyna, 2012; Iwashyna et al., 2009; Lomi et al., 2014). The field of health care 
provides an ideal setting to conduct our analysis also because hospital performance is welldocumented, and allows direct interorganizational comparison. Rich sources of high quality information are also available and publicly accessible on patterns of interorganizational collaboration - as we define it below.

Health care in Italy is organized on a regional basis according to federal principles. Thus, the regional health system in Lazio is part of the Italian National Health Service (INHS), a publicly funded health care system providing universal coverage free of charge at the point of service. The health system in Lazio is partitioned into twelve Local Health Units (LHUs). LHUs are vertically integrated public organizations funded by the region through a capitated budget and responsible for the provision of a wide range of services in geographical areas with target populations of approximately 500,000. LHUs represent the reference markets from which hospitals derive basic input resources - namely, patients and budgetary funds - and to which hospitals sell their services. The majority of hospitals in Italy are publicly owned, but a significant number of investor-owned, and not-for-profit hospitals also receive public funding through a contracting system with the INHS. Both public and private hospitals in Lazio enjoy high levels of administrative and managerial autonomy in the organization and delivery of health care services. Hospitals are accountable to regional health authorities for performance results and use of resources within the limits of global budgets yearly assigned to them.

Because they operate in a sector that is jointly technical and institutional (Scott and Meyer, 1983), hospitals represent an almost ideal example of organizations whose performance, status, and social legitimacy depend on their ability to involve partners in joint problem solving activities in the interest of patients' health (Iwashyna et al., 2009; Provan and Milward, 1995). For this reason, the ability to access knowledge resources across organizational boundaries and to involve partners in joint problem-solving activities and arrangements is particularly important for hospital organizations. One way in which two hospitals may be involved in joint problem solving activities is through direct patient transfers, whereby (in)patients discharged from one ("sender") hospital are 
admitted to another ("receiver") hospital. Patient transfer is one of the most important forms of inter-hospital collaboration that has been only recently investigated in the health care literature on interorganizational networks (Lee et al., 2011; Iwashyna and Courey, 2011; Lomi and Pallotti, 2012).

The intended objective of patient transfers is to serve the best interest of patients: In most cases transfers occur when a hospital has limited physical capacity available, or patients with complex pathologies for which no adequate technologies or clinical competences are available, or when a hospital has patients with therapeutic needs that may be met more effectively in another hospital. In all these cases, the choice of destination for the patient involves an explicit partner selection decision: A sender hospital may choose from a number of recipient hospitals for the same patient. Discretionary patient transfers also represent important opportunities of reciprocal learning, as they imply intense collaboration and coordination between partners involved in the transfer. This coordination involves transfer of clinical information (carried by documentation accompanying patients being transferred), as well as transfer of knowledge about clinical and organizational practices of the partner hospital. These are rather specific information, because they concern the clinical and organizational history of the patients being transferred. Completing a transfer requires not only a physical and technical infrastructure making the transfer operationally possible (Iwashyna, 2012), but also a relational infrastructure based on a complex coordination and information sharing process between partner hospitals (Gittel, 2002; Bosk, Veinot, and Iwashyna 2011).

We interpret ties established between hospitals through patient transfers as proxies for the underlying propensity of hospitals to collaborate and learn from others (Lee et al., 2011; Veinot et al., 2012; Iwashyna and Courey, 2011). As one of the medical directors of a large university hospital reported in an interview: "Patient transfers are made possible only with high levels of coordination and communication between partner hospitals." Lack of adequate coordination between hospitals involved in patient transfers has predictable adverse consequences (Lee et al., 
2011). Inter-hospital patient transfers represent also an opportunity for partner hospitals to learn from others and acquire new competencies. For example, the medical staff of the receiving hospital might learn from receiving a patient that underwent an innovative procedure or treatment protocol in the sending hospital. The director of a clinical ward in one of the hospitals in our sample revealed that: "Transferring patients is an important learning experience. Preparing the records that accompany the patient is an extremely delicate and important activity. The doctors who complete and sign the documents put a lot of effort into it. Sometimes they do it to impress the receiving hospital. These documents often contain hundreds of pages (containing information on referrals, diagnostic tests, etc.).”

Our analysis relies on both primary and secondary data sources. We obtained secondary data from archival sources contained in the Regional Hospital Information System database (SIO) which provides information on patients admitted by any hospital in the region. We supplemented official sources with a questionnaire-based survey, administered to all the hospitals in Lazio and designed to collect information on a number of dimensions of organizational structures, resources and hospital activities. We also conducted semi-structured interviews with hospital doctors, managers and executives to improve our contextual understanding of inter-hospital collaboration via patient transfers among hospital organizations. Our final sample includes 91 hospitals corresponding to 8,190 dyadic observations which we analyze in the empirical part of the study.

\subsection{Variables and Measures}

\section{Dependent variable}

The main dependent variable of our study is based on a specific aspect of organizational performance. Almost regardless of the kind of organization, performance is a multidimensional concept that is difficult or undesirable to reduce to a unique measure (Barney, 2002). This is particularly the case for hospitals, organizations for which legitimacy, institutional standing and, 
ultimately, performance depend on their ability to satisfy expectations expressed by a variety of external stakeholders (Ruef and Scott, 1998).

For the purpose of this study we focus on a general measure of organizational performance that has been widely used in the Italian health care industry in recent years: the Comparative Performance Index (CPI). Among available performance indices, the CPI captures both technical and social dimensions of organizational performance because it takes into account operational aspects of the supply of health care services, and because it is explicitly comparative. Thus, the CPI is an ideal measure as it provides information that can be used by a variety of stakeholders to assess hospitals' performance. It is used by health authorities, as CPI allows comparing the effectiveness of a hospital relative to that of a standard set of hospitals at a regional level. Health care authorities use the CPI for budget allocation purposes, and hence is a measure whose variation tends to attract management attention. The CPI index is also used by hospital managers to evaluate the position of a hospital in the reference market for health care services, as the CPI varies with the competitiveness of hospitals considered as benchmark.

Following the definition of the Italian Ministry of Health, the CPI is a composite index that measures the effectiveness - in terms of length of stay - of a hospital relative to the average effectiveness of a reference set of hospitals (typically, at regional level) with an analogous composition of cases treated, where cases are categorized into Diagnosis Related Groups (DRGs). CPI is computed as:

$$
\mathrm{CPI}_{\mathrm{j}}=\sum_{\mathrm{i}=1}^{\mathrm{n}_{\mathrm{c}}}\left[\mathrm{d}_{\mathrm{i}} * \mathrm{~N}_{\mathrm{i}}\right] / \sum_{\mathrm{i}=1}^{\mathrm{n}}\left[\mathrm{D}_{\mathrm{i}} * \mathrm{~N}_{\mathrm{i}}\right]
$$

Where $d_{i}$ indicates the average length of stay of DRGi numbered in hospital $j$; $D_{i}$ indicates the average length of stay of DRGi numbered in the reference set of hospitals with an analogous composition of cases treated; $\mathrm{N}_{\mathrm{i}}$ indicates the number of discharges of DRGi numbered in the 
reference set of hospitals; $n$ indicates the number of DRGs in the reference set of hospitals, and $n_{c}$ indicates the number of common DRG overlapping between hospital $\mathrm{j}$ and the reference set of hospitals (Gianino et al. 2006). The CPI takes the value of 1.0 for hospitals whose performance is aligned with the performance of the reference set of hospitals. The CPI takes values that are smaller (larger) than 1.0 for hospitals that perform better (worse) than the regional standard. Finally, we note that the CPI is a particularly useful measure of hospital performance for at least two reasons. The first is substantive. By keeping the case mix into account, the CPI allows comparison of hospitals that would be otherwise too different to compare. The second is institutional. The CPI is used by public health authorities explicitly to compare different hospitals and to link resource incentives to clear performance targets.

We study how interorganizational differences in performance vary with three main independent variables of interest: (i) strength of direct social interaction; (ii) social proximity as measured by co-membership in cliques, and (iii) structural equivalence, or positional similarity in the relevant interorganizational network. More precisely, we compute the difference between the best performer and the worst performer within each organizational dyad. In this way we can test our performance assimilation hypotheses while at the same time have a sense of the directionality of the effect. If the effect of a covariate is to reduce the difference in performance between the members of a dyad, then it means that assimilation happens "from below" - i.e., the worse performing tends to approach the better performing partner. In this case, the performance spillover effect would be positive as we can detect directional performance assimilation effects.

Less informally, suppose that $\pi_{t}$ and $\pi_{\mathrm{j}}$ are the levels of performance attained by organization $\mathrm{i}$ and $\mathrm{j}$, respectively. Suppose, further, that $\pi^{*}=\max \left(\pi_{\mathrm{i}}, \pi_{\mathrm{j}}\right)$ is the best level of performance observed within the ij-th dyad. Then the average difference in performance within a dyad is: $\Delta\left(\pi_{\mathrm{ij}}\right)=1 / 2\left[\left(\pi^{*}-\pi_{\mathrm{i}}\right)+\left(\pi^{*}-\pi_{\mathrm{j}}\right)\right]$. When $\mathrm{i}$ is the best performer (i.e., $\left.\pi^{*}=\pi_{\mathrm{i}}\right)$, then $\Delta\left(\pi_{1 \varphi}\right)=1 / 2\left(\pi^{*}-\pi_{\mathrm{j}}\right)$. When $\mathrm{j}$ is the best performer (i.e., $\left.\pi^{*}=\pi_{\mathrm{j}}\right)$, then $\Delta\left(\pi_{\mathrm{i \varphi}}\right)=1 / 2\left(\pi^{*}-\pi_{\mathrm{i}}\right)$. In either case, a decrease in $\Delta\left(\pi_{\mathrm{ij}}\right)$ implies not only that $\mathrm{i}$ and $\mathrm{j}$ are becoming more similar, but also that 
assimilation happens "from below," i.e., the low performing member of the dyad is drawn toward the higher level of performance of the partner (i.e, either $\pi_{\mathrm{i}} \rightarrow \pi^{*}$, or $\pi_{\mathrm{j} \rightarrow \pi^{*}}$ ). A symmetric argument holds if $\Delta\left(\pi_{\mathrm{ij}}\right)$ increases. In this case, the performance of partners diverges as partnership accentuates differences in performance between members of the dyad.

\section{Independent variables}

We use information on the network of inter-hospital patient transfers to compute the three main independent variables of interest. More precisely, by using public data on inter-hospital patient flows, we constructed an asymmetric matrix $\left(\mathrm{V}=\left[\mathrm{v}_{\mathrm{ij}}\right]\right)$ of size $91 \times 91$. The matrix contains in rows (columns) the hospitals sending (receiving) patients, and in intersection cells $\left(\mathrm{v}_{\mathrm{ij}}\right)$ the number of patients transferred from the row hospital i to the column hospital $\mathrm{j}$. This corresponds to 8,190 dyads of sending/receiving hospitals (that is $n(n-1)$, where $n=91$ ). The volume of transferred patients within dyads ranges from 0 to 525 patients, with an average of 1.6 (standard deviation $=$ 12.69). An illustrative graphical representation of this network is provided in Figure 1.

- Insert Figure 1 about here -

The independent variables of theoretical interest are based on different aspects of the collaborative relationship observed between hospitals. As we discuss and show in the remainder of this section the independent variables of theoretical interest are not different measures of the same phenomenon, but measures of the different phenomena underlying our hypotheses.

We measure the strength of direct social interaction by using the volume of patient transfers between hospitals, because the number of patients transferred between partner hospitals is a reliable proxy for the intensity of collaboration via resource exchange (Gittell, 2002) ${ }^{1}$.

\footnotetext{
${ }^{1}$ To rule out the possibility that our results are affected by the tendency of larger hospitals to send and receive more patients than smaller hospitals, we also used an alternative measure of the strength of interaction. More precisely, we scaled the number of patient transfers by the number of admitted patients for each hospital and
} 
Proximity in social groups is measured by using joint membership in organizational subgroups, or cliques. In network terms, cliques are defined as maximally complete sub-sets of actors with three or more members (Wasserman and Faust, 1994) ${ }^{2}$. Because clique membership is a discrete concept, to compute co-membership in cliques we first binarized the original (valued) inter-hospital patient transfer matrix and then found all the possible cliques in the network. ${ }^{3}$ Comembership was then computed by simply counting the number of cliques in which any two hospitals in the sample are jointly members.

We rely on the notion of clique co-membership to measure social proximity because: "In a clique, the outcomes for firms are fundamentally intertwined with those of other firms that belong to the same clique" (Rowley et al, 2004: 454). Behavior of organizations encountering each other in multiple cliques will be more likely to be interdependent because of the increased level of mutual awareness inherent in the co-membership in multiple cliques, and because of the dependence on common sources of information represented by multiple shared partners.

Finally, to measure positional similarity we rely on the original insight of White, Boorman and Breiger (1976), and follow a strategy that is frequently adopted in the blockmodel analysis of interorganizational fields (DiMaggio, 1986). As a continuous measure of positional similarity we use the correlation of the rows and columns of the inter-hospital patient transfer network, a widely accepted measure of similarity in the relational profiles of the organizations in the network ${ }^{4}$. The result is a matrix $\mathrm{S}$ of correlation coefficients in which the value of the cells $\left(\mathrm{s}_{\mathrm{ij}}\right)$ varies between -1 and +1 . The closer $s_{\mathrm{ij}}$ is to +1 , the more $\mathrm{i}$ and $\mathrm{j}$ have similar relational profiles, i.e. - in the language of social network analysis - the more they are structurally equivalent.

included this new variable in our empirical model specification. By all practical purposes, the results obtained by using this normalization are the same as those reported in the paper.

2 This is the most restrictive and mathematically defensible clique structure. It requires that all members of the subgroup are tied to every other member such that the maximal social distance between all pairs is one. This definition maps on precisely to the definition of cliques as maximally complete sub-graphs.

${ }^{3}$ We dichotomized the patient transfer matrix by setting all the non-negative entries in the weighted adjacency matrix equal to one. Note that the average cell value is below 2 (See Table 1). Hence, different dichotomization rules (for example based on the mean cell value) would produce almost identical network structures.

${ }^{4}$ The relational profile similarity measures that we compute is identical to the initial matrix of correlation produced by CONCOR, a widely used algorithm used to partition social networks into structurally equivalent sets of nodes (Arabie, Boorman, and Levitt, 1978). We do not use CONCOR because we are interested in a continuous measure of similarity in network positions rather than in a discrete partition. 


\section{Control variables}

Variation in interorganizational performance cannot obviously be explained only by networkrelated effects at the dyad, clique, and global network levels. We control for the effects of two broad categories of factors that may influence organizational performance and, therefore, confound the relation between network effects and performance similarity between organizations. The first category involves organization-specific covariates such as size (number of beds and number of discharges), technological endowments (technology), managerial orientation (administrative intensity), capacity utilization (occupancy rate), task complexity (complex DRG), service mix (number of specialties), and type of assistance (level of care). Within this first group of covariates, Complex DRG is likely to play a particularly important role in our analysis because it captures salient operational, clinical and economic differences between hospitals (Lynk, 2001). The second category of covariates includes broader institutional and competitive forces. We control for the former by including a variable that is equal to 1 if sender and receiver hospitals belong to the same institutional category (referring to the classification used by the health authorities), as well as joint membership in Local Health Units (LHU membership). We capture the latter by measuring the extent of competitive interdependence between pairs of hospitals in terms of number of patients they treat who come from the same administrative areas, or LHUs (Sohn, 2001; 2002); we also control for geographic distance between each pair of hospitals.

Table 1 summarizes essential information on the variables included in our empirical model specifications. Some variables are defined at the organizational level (i.e., monadic variables) while others refer to hospital dyads (i.e., dyadic variables). Values for the dependent variable (CPI) are computed for year 2004, while values of all the other variables are computed for year 2003.

- Insert Table 1 about here - 
Table 2 reports correlation coefficients among all the variables included in our empirical model specifications.

- Insert Table 2 about here -

The descriptive figures reported in Table 2 help us to clarify a point that may be of potential empirical and conceptual concern. The three variables of main theoretical interest (variable 2: Strength of social interaction; variable 3: Social proximity, and variable 4: Positional similarity) are only weakly correlated. This means that - empirically - the three variables vary with at least some degree of independence. This is important because a high correlation might make it difficult to identify individual effects. In our sample, the weak correlation $(0.065)$ between strength of social interaction and positional similarity simply reveals that organizations occupying the same network position (structurally equivalent organizations) are not necessarily directly connected (DiMaggio, 1986). This descriptive result is consistent with prior research demonstrating that strength of social interaction (or "cohesion") and positional similarity (or "structural equivalence") are distinct theoretical and analytical constructs (Burt, 1978). The relatively weak correlation (0.183) between strength of social interaction and social proximity reveals that organizations linked by strong ties belong to cliques that do not necessarily contain the same members. Finally, the correlation between social proximity and positional similarity (0.138) is relatively weak because - while cliques may be considered as a special kind of jointly occupied network position (Burt, 1978: 189), they assume a direct connection among all the members of the cliques. Clearly, in our data structurally equivalent organizations are not all directly connected, i.e., are not members of cliques.

\subsection{Empirical Model Specification}

The outcome of interest in this study is similarity in performance between organizations. As a consequence, the most appropriate unit of analysis is the individual dyad (Mizruchi and Marquis, 
2006). The dyad is the smallest possible unit at which similarities and differences due to collaboration or other social processes can be detected.

Given the dyadic structure of the data and the continuous nature of our dependent variable, we report results based on estimates of the parameters in models based on a fixed-effects regression structure. This is the generally accepted modeling practice to control for lack of independence among the dyads in dyadic models (Mizruchi, 1989; Stuart, 1988). The basic model considered here is:

$\mathrm{E}\left(\mathrm{Y}_{\mathrm{ij}}\right)=\left(\alpha+\beta \mathrm{T}_{\mathrm{ij}}+\not \mathrm{P}_{\mathrm{ij}}+\theta \mathrm{S}_{\mathrm{ij}}+\delta \mathrm{X}_{\mathrm{ij}}+\eta_{\mathrm{i}}+\varepsilon_{\mathrm{ij}}\right)$

where $Y_{i j}$ is a vector reporting observed differences in performance as discussed above (CPI differences) among each and every organization in the sample such that $Y_{i j}=\Delta\left(\pi_{\mathrm{ij}}\right)$, as defined above; $\mathrm{T}_{\mathrm{ij}}$ is the strength of direct social interaction or the number of patients that hospital $\mathrm{i}$ transfers to hospital $\mathrm{j}$; $\mathrm{P}_{\mathrm{ij}}$ indicates social proximity, or the number of cliques that hospital i shares with hospital $\mathrm{j}$ as defined by the adjacency matrix of overlapping cliques; $S_{i j}$ indicates the degree of positional similarity (structural equivalence) between hospital $\mathrm{i}$ and hospital $\mathrm{j}$; $X_{i j}$ summarizes the effect of covariates included to control for organizational and institutional variables; and $\eta_{i}$ is a set of organization-specific fixed effects. Finally, $\varepsilon_{i j}$ is an error term assumed to follow a normal distribution with zero mean. For benchmarking purposes, we test (2) against a restricted version (3) in which we assume $\beta=\gamma=\theta=0$, that is, network effects are irrelevant at all levels:

$\mathrm{E}\left(\mathrm{Y}_{\mathrm{ij}}\right)=\left(\alpha+\delta \mathrm{X}_{\mathrm{ij}}+\eta_{\mathrm{i}}+\varepsilon_{\mathrm{ij}}\right)$ 
Organizations may not react to interorganizational peer effects only by becoming more similar to their (i) associates; (ii) clique co-members and (iii) structurally equivalent others. It is possible that when the intensity of peer pressure reaches very high levels, organizations may find it useful to implement differentiation strategies (Deephouse, 1999). To account for this possibility, and as a robustness check, we also fit a second-order polynomial regression in which the key predictors $\mathrm{T}_{\mathrm{ij}}$, $\mathrm{P}_{\mathrm{ij}}$, and $S_{i j}$ are raised to the power of 2 . Equation 2 then becomes:

$$
\mathrm{E}\left(\mathrm{Y}_{\mathrm{ij}}\right)=\left(\alpha+\beta_{1} \mathrm{~T}_{\mathrm{ij}}+\beta_{2} \mathrm{~T}_{\mathrm{ij}}^{2}+\gamma_{1} \mathrm{P}_{\mathrm{ij}}+\gamma_{2} \mathrm{P}_{\mathrm{ij}}^{2}+\theta_{1} \mathrm{~S}_{\mathrm{ij}}+\theta_{2} \mathrm{~S}_{\mathrm{ij}}^{2}+\delta \mathrm{X}_{\mathrm{ij}}+\eta_{\mathrm{i}}+\varepsilon_{\mathrm{ij}}\right)
$$

Because our data are dyadic, covariates representing continuous organizational variables enter the model specification as absolute differences between levels of the variable observed for "sender" i and "receiver" $\mathrm{j}$ hospitals. The smaller this difference, the more similar are the hospitals with respect to the specific attribute that is being considered. For covariates taking on categorical and binary values we compute an exact match indicator to identify organizations belonging to the same category.

We use a fixed-effects approach to address a major concern with dyad-oriented observation schemes: the observations are not independent because each actor in the network appears in multiple dyads, creating complex dependencies across observations (Stuart, 1998). Because of the presence of complex dependence structures, coefficient estimates will be consistent, but the standard errors may be estimated incorrectly. In empirical studies of organizational networks this problem is typically alleviated by introducing a fixed effect for each source or recipient of a relationship, by clustering the standard errors at the sender level and applying the Hubert-White correction for heteroskedasticity (Owen-Smith and Powell, 2004; Reagans and McEvily, 2003; White, 1980). We adopt the same analytical strategy, which also serves as a control for additional sources of unobserved heterogeneity across hospitals. 


\subsection{Model estimation}

The results that we discuss in the next section (reported in Table 3, see below) are obtained by estimating a fixed-effects (FE) regression with robust standard errors, using specification (4) above, that is, including both linear and quadratic terms for the network factors (model specification Q, “Quadratic"). For comparison purposes, we also considered equation (2) (model L, “Linear”) and its restricted version (3) (model E, "Empty" which does not include network effects) as possible alternative specifications. Statistical tests (Wald tests) rejected the hypothesis that the linear network effects (strength of direct relations, co-membership in cliques, network positions) are jointly insignificant, and similarly, that the quadratic terms of these same network variables are jointly insignificant, thereby leading to the conclusion that equation (2) (Model L) is to be preferred to (3) (Model E), and (4) (Model Q) to (2) (Model L).

Following standard econometric practice, we also considered alternative approaches, notably pooled OLS and random-effects (RE) estimations ${ }^{5}$. Model specification tests provided evidence that, due to heteroskedasticity in the errors from the regressions, pooled OLS performs less well than either RE or FE. In turn, the choice of the FE estimator against RE, is due to rejection of the over-identifying restrictions involved in the RE approach. Indeed both FE and RE estimators assume that the regressors are uncorrelated with the idiosyncratic error, but the latter also require organization-specific effects to be orthogonal to other regressors, an assumption that turns out to be excessively strong for our data. For these reasons, we conclude that the FE estimator is to be preferred, although for all three specifications, coefficients are highly similar across RE and FE in terms of their sign, size, and significance.

\section{ANALYSIS}

\subsection{Results}

\footnotetext{
${ }^{5}$ The results of pooled OLS and random effects were included in an earlier version of the paper and are available from the Authors upon request.
} 
Because the effects we report are stable across specifications, we organize the discussion of the results around the full model (Model Q) in Table 3 reporting the fixed-effects estimates of models in which the dependent variable is the absolute difference between the best and worst performer within each dyad. As we explained, performance is measured in terms of the Comparative Performance Index, CPI - a widely used and generally accepted measure of hospital performance.

- Insert Table 3 about here -

Because we are estimating the effect of each variable on the gap in performance between (sending) hospital $\mathrm{i}$ and (receiving) hospital $\mathrm{j}$, a negative coefficient indicates that an increase in the independent variable will lead to a reduction of this gap, that is, to more similar levels of performance as measured by the CPI indicator. It bears repeating here that a negative effect also implies - by construction - that the reduction in performance difference within each dyad happens "from below," i.e., through an increase in the performance of the worse performing organization which tends to assimilate the performance of its better performing partner.

Concerning our variables of theoretical interest, we find that the strength of direct social interaction, measured by the number of patient transfers $\mathrm{T}_{\mathrm{ij}}$, has no discernible effect on performance differences: bilateral exchanges, however numerous and frequent, are insufficient to generate spillover effects that affect similarity in hospitals' CPI. One possible interpretation of this result is that individual ties are relatively unimportant when not considered as embedded in more complex network structures (Uzzi, 1996). In other words, individual ties that are not part of more complex dependence structures are unlikely to affect performance differentials.

Instead, co-membership in network subgroups $P_{i j}$ is highly significant in all models, and its quadratic effect is also significant, though both are small in size. The negative sign of the linear effect indicates that greater social proximity as measured by greater embeddedness in common cliques leads to more similar performance, while the positive effect of the quadratic term indicates 
that the relationship is convex. A minimum is attained when $\mathrm{P}_{\mathrm{ij}}=-\left(-\frac{0.003565}{2 \cdot 0.000098}\right)=18.19$, a value located at about the midpoint of the range over which social proximity is defined (0-37: see Table 1). Beyond this level, further increases in the number of shared cliques will increase the gap in performance between sender and receiver. In other words, the assimilation effects of social proximity reach a limit when the number of cliques in which two organizations share membership is approximately 18. After this limit is reached, the countering effects of over-embeddedness sets in, and the performance of organizational partners begin to diverge (Figure 2, left panel). In other words, over-embeddedness triggers differentiation which, in turn, might produce differences in performance. This may be the case because "over-embeddedness" is known to be associated with decline in performance (Uzzi, 1997). An alternative conjecture could be that over-embeddedness stimulates the formation of weak ties in an attempt to sample the experience of distant and hence less familiar others (Baum et al., 2005).

Finally, we find that positional similarity has a linear negative effect, so that a unit increase in it will reduce the gap in performance between $\mathrm{i}$ and $\mathrm{j}$ by approximately $2.6 \%$ (Figure 2, right panel). In other words, similarity in the relational profiles of two organizations (their structural equivalence) makes them more similar in terms of their performance.

- Insert Figure 2 about here -

Regarding the control variables, we find that parameter estimates have intuitively predictable signs. Because "size" of a hospital is a complex concept that can be measured in different ways, we included two variables that capture different aspects of the size of a hospital. More specifically, number of staffed beds captures the aspect of capacity installed, whereas number of discharges (which is equal to the number of admitted patients) captures the throughput aspect of a hospital's dimension. The results show that in both cases differences in organizational size do not affect 
differences in performance, nor do differences in technology endowments and level of care. Differences in the number of specialties have only a weak negative effect when network effects are introduced in specifications (L) and (Q), indicating that hospitals with a large number of specialties and hospitals with a small number of specialties do not differ in terms of performance. All the rest being equal, differences in administrative intensity, or percentage of managerial staff on total workforce, have a positive effect, corresponding to larger performance gaps between sender and receiver hospitals, though this result is only significant at the 5\% level. Differences in occupancy rates also have a strong and positive effect on CPI gaps, suggesting that hospitals using their available beds capacity to very different degrees will have very different performance. Likewise, differences in the extent to which hospitals handle complex cases also result in very different performance outcomes. As we expected, the effect of complexity (or the proportion of complex DRGs over the total amount of DRGs) is particularly strong. Complex DRG is typically used to indicate patient conditions that are not accounted for by patients' DRG classifications and that result in higher clinical variation and financial risks for hospitals dealing with these cases (Slattery and Harewood, 2012; Tahari et al., 2001). This result may be taken as evidence of the fact that the economics of hospitals dealing with cases that are administratively more complex is quite different from that of simpler hospitals (Lynk, 2001).

Geographical distance has a strong negative effect, meaning that hospitals located close to each other do not tend to attain similar levels of performance that are reached, instead, by those located further apart. Joint LHU membership has no significant effect on differences in organizational performance. The effect of competitive interdependence is negative and significant, indicating a strong effect on the reduction of performance differentials of competitive constraints and therefore, dependency on common resources (patients, in our case). Greater competitive interdependence corresponds to greater performance similarity - a result aligned with our understanding of how economic competition shapes the world of organizations. Finally, institutional type is only slightly significant under the empty model (E), but loses its significance 
when network effects are introduced in specifications (L) and (Q). Therefore, similarity in institutional form does not significantly affect differences in performance.

We have repeated the same analysis after standardizing the covariates to learn if there were significant differences in the magnitude of the estimated parameters (results not reported here). With the partial exception of the effect of complex DRG, the magnitude of the estimated effects associated with the covariates of theoretical interest are comparable with the magnitude of the effects of the other control covariates included in the model and, in fact, they are frequently stronger. For example, in the standardized model social proximity is more than two times stronger as the effect of organizational size (measured in terms of number of beds and number of discharged patients) - one of the variables that is typically associated with powerful differences between organizations (Blau, 1970; Kalleberg and van Buren, 1996). In the standardized model not reported here, the effects of structural equivalence are approximately 4 times larger than the effect of LHU membership - perhaps the most powerful source of institutional isomorphism in the interorganizational field under investigation.

\section{DISCUSSION AND CONCLUSIONS}

A central insight produced by studies of interorganizational networks is that organizational structures, behaviors and performance are all shaped by social connections that organizations develop and by positions that they occupy in networks of exchange relations (Mizruchi and Marquis, 2006). A second important insight from institutional theories is that interdependent organizations tend to assimilate each other knowledge and emulate each other behavior, hence becoming more similar in terms of structures, behavioral orientations and, ultimately, outcomes. This is the essence of mimetic isomorphism - the tendency of organizations to conform to network partners so clearly identified by DiMaggio and Powell (1983). In the case of mimetic isomorphism the tendency of organizations to become similar is not produced by state regulation (coercive isomorphism) or by the diffusion of institutional norms (normative isomorphism), but by the active 
adoption of practices that are expected to be beneficial. What we have added in this paper is detail on the possible mechanisms underlying mimetic isomorphism and about the level at which these mechanism effectively operate.

In the current study we combined these two major insights into a "network institutionalism" framework that: "Emphasizes relationships - which are not reducible to individual attributes - as the basic unit of explanation" (Ansell, 2008: 76). We adopted this framework to develop the claim that if the effects of network influence on organizational performance exist, then the difference between the performances of interdependent organizations should be smaller than if there were no influence. We then asked: To what extent and at what level of analysis are organizations actually affected by the performance of their network peers? This question corresponds to asking how far influence effects that operate through networks spill over. Possible answers to this question involve explicit assumptions about the level at which networks exert their influence on organizational performance and about the mechanisms that swathe such influence. We address this general question in a specific empirical context using data that we have collected on performance and exchange relations between hospital organizations.

We found that performance spillover effects are highly differentiated and vary significantly across network levels. More specifically, we found that the strength of direct social interaction is not significantly associated with performance spillover effects between connected organizations: interorganizational performance differentials are not necessarily reduced by the strength of direct collaborative relationships between partners. We believe that the fact that direct dyadic dependence generated by network ties does not seem to explain dyadic differences is a new result that opens new directions for future research about the level at which network effects operate.

Joint membership in cliques, on the other hand, has a clear non-linear effect on performance spillover: as social proximity increases interorganizational performance differentials decrease at first, then reach a minimum beyond which further increases in social proximity are accompanied by an increase in performance differentials. This is the case because simultaneous membership in 
multiple cliques exposes organizations to common sources of influence and helps them to form a frame of comparability within which they are better able to assess and appreciate the value of organizational practices, structures and behaviors enacted by partners. In their study of the diffusion of innovative practices within health care organizations, Ferlie et al. (2005) produced similar findings. They found that social and cognitive boundaries created around professional groups, or communities of practices, favored the diffusion of clinical practices within those groups. Our results, however, show that the influence effects of membership in social groups, or settings, operate up to a point beyond which differentiation processes are activated that - we show - produce different behaviors, and hence different outcomes.

The strongest boundary around processes of network influence, however, is represented by the occupation of joint network positions. We found that as similarity in network positions that two organizations occupy increases, their interorganizational performance differentials decrease linearly. This result is coherent with the lack of cognitive processes of differentiation based on mutual awareness and direct contact that structural equivalence does not necessarily require in order to produce its (influence) effects. We interpret this result as evidence that the range of network influence is not confined within localized network substructures - i.e., dyadic or sub-group network levels - but diffuses globally.

We showed that these results are robust with respect to a considerable variety of factors that may be responsible for observed interorganizational performance similarities including competitive interdependence, similarity in institutional arrangements, structural features, and in capacity constraints.

The results that we reported contribute to our understanding of interorganizational networks by showing how "local" (relation-based), "mid-range" (setting-based) and "global" (positionbased) mechanisms jointly affect performance differentials between interconnected organizations. In the context of the continuing debate over the level at which network effects actually occur 
(Mizruchi and Marquis, 2006), we showed that network influence is more likely to produce observable results at a global level.

In a more speculative mode, our findings are relevant for the broader field of research on performance differences across organizations in industry. Economic theory predicts that performance differentials, if any, should disappear over time as a consequence of competition. In the long-run, any remaining differential would be due to rents extracted from idiosyncratic or nonreproducible assets such as natural resources, or to barriers to entry and market power. The literature on interorganizational networks cited above stresses social processes grounded in social influence and learning which, though distinct in nature from competition, also produce a leveling effect and ultimately obscure performance differences. Persisting differences in performance, though often observed, are thus difficult to explain.

Our study provides some fresh insight into the way network structures and positions may sometimes maintain performance differences. Similarity of positions in the network contributes to reduce performance differences, and so does social proximity as measured by co-membership in cliques; so far, our results are in line with the interorganizational networks literature. Yet, we also show that social proximity exerts a leveling effect only up to a point, after which overembeddedness widens performance gaps again. Over-embeddedness in network sub-groups at meso level thus seems to be a mechanism that can maintain, and possibly even increase, performance differences, beyond all other tendencies to reduce them. By bringing it to light, our work contributes to furthering reflection on the reasons of persisting differences across organizations. We are aware, however, that network effects are likely to be contingent on the specific context and the specific aspect of organizational performance that may be of interest in any one situation. It would thus be useful to perform further tests, in particular by using dynamic panel data, which would take into account the temporal dimension of processes of change and persistence. More complex, extradyadic statistical interdependencies could also be taken into account. 
We have focused on organizational learning as one possible effect induced by interorganizational collaboration, i.e., organizational learning, because we were interested in understanding the social mechanisms associated with performance assimilation. Clearly, interorganizational relations may be established for a variety of reasons such as, for example, the need to meet legal-political requirements (necessity), to reduce environmental uncertainty (stability), to economize on transactions (efficiency), to pursue common or complementary goals (reciprocity), to gain credibility and respectability through association (institutional), and to preserve autonomy (asymmetry) (Oliver, 1990). The results of our study extend naturally to other kinds of interorganizational collaboration, to the extent that these different motivations encourage and support sharing of knowledge and experiences between partners. Clearly, the empirical extension of our results is limited by the fact that we have chosen to observe only a specific kind of collaborative relation between hospitals. But hospitals collaborate also with other kind of health care organizations (for example, biological laboratories and primary care practices) and patient exchange is obviously not the only form of collaboration. We focused on this specific relation because prior literature has documented the importance of relational coordination between hospitals via patient exchange (Lomi et al., 2014) and because prior research instructs us that patient exchange relations facilitate interorganizational learning by promoting the sharing of clinical and organizational information that would be otherwise difficult to obtain (Lee et al., 2011; Iwashyna and Courey, 2011). In our study this is important because interorganizational learning is the main mechanism underlying the reduction of interorganizational performance differentials that our analysis clearly documents.

The main limitation of the study is inherent in the cross-sectional nature of the research design which prevents strong inferential conclusions. We have documented a number of statistical associations that are consistent with our hypotheses, but cross-sectional data do not allow us to rule out the possibility that organizations associate on the basis of similarity in performance, thus producing through social selection the result that we have ascribed to social influence mechanisms. 
As it has been long recognized, only longitudinal research designs support analyses that may help do disentangle these two sub-processes of network evolution (Leenders, 1997). We note - however - that the hypothesis of social selection on the basis of similarity in attributes would be consistent with a strong "short range" effect at the dyadic level - the level at which social selection acts more directly. We do not find this result in our data as the strongest spillover effects are associated with joint occupancy of network positions that - as we have shown - are clearly distinct from direct dyadic relations. Also, social selection hypotheses would need to be based on the assumption that partner selection decisions are driven consciously and explicitly by considerations of performance similarity - an assumption that does not seems plausible in the present study.

Despite the potentially important limitations that we have highlighted, we think it is fair to say that the findings reported in this paper are useful as they invite reflection on the dual role of interorganizational networks both as barriers to, and as conduits for, performance spillover effects. Our study was motivated by fundamental questions about the range of network effects - or about how far network-based processes reach out to affect interorganizational performance differentials. "Quite far" is the answer that the results reported in this study seem to support. 


\section{References}

Ahuja, Gautam, 2000. “Collaboration networks, structural holes and innovation: A longitudinal study”. Administrative Science Quarterly, 45: 425-455.

Alba, Richard D. and Charles Kadushin, 1976, "The intersection of social circles. A new measure of social proximity in networks". Sociological Methods \& Research, 5: 77-102.

Ansell. Christopher, 2008, "Network Institutionalism". In Sarah A. Binder, Rod A.W. Rhodes, and Bert A. Rockman (Eds). The Oxford handbook of Political Institutions. Oxford University Press.

Arabie, Phipps, Boorman, Scott A. and Paul R. Levitt, 1978, “Constructing blockmodels: How and why". Journal of Mathematical Psychology, 17, 21-63.

Barney, Jay B., 2002, Gaining and sustaining competitive advantage. Prentice-Hall, Inc., NJ.

Baum, Joel A.C. and Paul Ingram, 2002, "Interorganizational learning and network organizations: Toward a behavioral theory of the firm". In Mie Augier and James G. March (ed.) The economics of choice, change, and organization. Essays in the memory of Richard M. Cyert. Cheltenham UK: Edward Elgar, pp. 191-218.

Baum, Joel A.C. and Christine Oliver, 1991, "Institutional linkages and organizational mortality". Administrative Science Quarterly, 36: 187-218.

Baum, Joel A.C., Andrew V. Shipilov and Tim J. Rowley, 2003, "Where do small worlds come from?" Industrial and Corporate Change, 12:697-725.

Beckman, Christine M. and Pamela R. Haunschild, 2002, "Network learning: The effects of partners' heterogeneity of experience on corporate acquisitions”. Administrative Science Quarterly, 47: $92-124$.

Blau, Peter M, 1970, “A formal theory of differentiation in organizations". American Sociological Review, 35: 201-218.

Blau, Peter M., and Joseph E. Schwartz, 1997 [1984], Crosscutting social circles: testing a macrostructural theory of intergroup relations. Orlando: Academic Press.

Bosk, Emily A., Tiffany Veinot and Theodore J. Iwashyna, 2011, "Which patients, and where: A qualitative study of patient transfers from community hospitals". Medical Care, 49(6): 592-598.

Breiger, Ronald L., 1974, “The duality of persons and groups”. Social Forces, 53: 181-190.

Burt, Ronald S. 1978. "Cohesion versus structural equivalence as a basis for network subgroups". Sociological Methods Research, 7(2): 189-212.

Burt, Ronald S., 1982, Toward a structural theory of action: Network models of social structure, perception, and action. New York: Academic Press. 
Burt, Ronald S., 1987, “Social contagion and innovation: Cohesion versus structural equivalence". American Journal of Sociology, Vol. 92(6): 1287-1335.

Burt, Ronald S. and Ilan Talmud, 1993, "Market niche”. Social Networks, 15:133-149.

Cohen, Wesley M. and Daniel A. Levinthal, 1990, "Absorptive capacity: A new perspective on learning and innovation”. Administrative Science Quarterly, 35(1): 128-152.

Cropper, Steve, Mark Ebers, Chris Huxham and Peter Smith-Ring, 2008, "Introducing interorganizational relations”. In Cropper, Steve, Mark Ebers, Chris Huxham and Peter Smith-Ring. (Eds) The Oxford Handbook of Interorganizational relation. Oxford, UK. Oxford University Press, pp. 3-25.

Deephouse, David L., 1999, "To be different, or to be the same? It's a question (and theory) of strategic balance”. Strategic Management Journal, 20: 147-166.

Davis, Gerald F. and Henrich R. Greve, 1997, "Corporate elite networks and governance changes in the 1980s”. American Journal of Sociology, 103(1): 1-37.

DiMaggio, Paul J., 1986, "Structural analysis of organizational fields: A blockmodel approach". Research in Organizational Behavior, 8: 335-370.

DiMaggio, Paul J. and Walter W. Powell, 1983, "The iron cage revisited: Institutional isomorphism and collective rationality in organizational fields". American Sociological Review, 48: 147-60.

Ebers, Mark, 1997, “Explaining inter-organizational network formation”. In Mark Ebers (Ed.) The formation of interorganizational networks. Oxford, England: Oxford University Press, pp. 3-40.

Fennell, Mary L., 1980, "The effects of environmental characteristics on the structure of hospital clusters." Administrative Science Quarterly, 25: 484-510.

Ferlie, Ewan, Louise FitzGerald, Martin Wood and Chris Hawkins, 2005, "The nonspread of innovations: The mediating role of professionals". Academy of Management Journal, 48(1): 11734.

Galaskiewicz, Joseph, 1985, “Interorganizational relations”. Annual review of sociology, 11: 281304.

Galaskiewicz, Joseph and Ronald S. Burt, 1991, "Interorganization contagion in corporate philanthropy". Administrative Science Quarterly, 36(1): 88-105.

Galaskiewicz, Joseph and Stanley Wasserman, 1989, Mimetic processes within an interorganizational field: An empirical test. Administrative Science Quarterly, 34: 454-479.

Gianino, Maria Michela, Roberto Russo, Roberta Siliquini, Gian Piero Icardi, Roberto Fora, and Giovanni Renga, 2006, "Public and Private in Italian Health Care: Trends and Market Quotas.” Italian Journal of Public Health, 3: 81-89. 
Gittell, Jody H., 2002, “Coordinating mechanisms in care provider groups: Relational coordination as a mediator and input uncertainty as a moderator of performance effects”. Management Science, 48(11): 1408-1426.

Greve, Henrich R., 1996, "Patterns of competition: The diffusion of a market position in radio broadcasting". Administrative Science Quarterly, 41: 29-60.

Gulati, Ranjay, 1995, "Social structure and alliance formation patterns: A longitudinal analysis. Administrative Science Quarterly, 40(4): 619-652.

Gulati, Ranjay and Martin Gargiulo, 1999, "Where do interorganizational networks come from?”. American Journal of Sociology, 104(5): 1439-1493.

Hallen, Benjamin L., 2008, "The causes and consequences of the initial network positions of new organizations: From whom do entrepreneurs receive investments?". Administrative Science Quarterly, 53: 685-718.

Han, Shin-Kap, 1994, "Mimetic isomorphism and its effect on the audit services market". Social Forces, 73: 637-664.

Hannan, Michael T. and John Freeman, 1989, Organizational Ecology. Cambridge, MA: Harvard University.

Haunschild, Pamela, 1994, "How much is that company worth? Interorganizational relationships, uncertainty, and acquisition premiums". Administrative Science Quarterly, 39: 391-411.

Haunschild, Pamela R., Christine M. Beckman, 1998, "When do interlocks matter? Alternate sources of information and interlock influence”. Administrative Science Quarterly, 43: 815-844.

Hedström, Peter, Rickard Sandell and Charlotta Stern, 2000, "Mesolevel networks and the diffusion of social movements: The case of the Swedish social democratic party". American Journal of Sociology, 106(1): 145-72.

Helper, Susan, John Paul McDuffie and Charles Sabel, 2000, "Pragmatic collaborations: advancing knowledge while controlling opportunism". Industrial and Corporate Change, 9(3): 443-488.

Ingram, Paul and Joel A.C. Baum, 1997, “Opportunity and Constraint: Organizations' Learning from the Operating and Competitive Experience of Industries”. Strategic Management Journal, 18: 75-98.

Iwashyna, Theodore J., 2012, “The incomplete infrastructure for interhospital patient transfer". Critical Care Medicine, 40(8): 2470-2478.

Iwashyna, Theodore J. and Anthony J. Courey, 2011, “Guided transfer of critically ill patients: Where patients are transferred can be an informed choice". Current Opinion in Critical Care, 17: 641-647. 
Iwashyna, Theodore J., Jason D. Christie, James Moody, Jeremy M. Kahn and David A. Asch, 2009, “The structure of critical care transfer networks". Medical Care, 47(7): 787-793.

Kalleberg Arne L. and Mark E. Van Buren, 1996, "Is bigger better? Explaining the relationship between organization size and job rewards". American Sociological Review, 61: 47-66.

Kraatz, Matthew S., 1998, "Learning by association? Interorganizational networks and adaptation to environmental change”. The Academy of Management Journal, 41(6): 621-643.

Larson, Andrea, 1992, "Network dyads in entrepreneurial settings: A study of the governance of exchange relationships". Administrative Science Quarterly, 37(1): 76-104.

Lee, Bruce Y., Sarah M. McGlone, Yeohan Song, Taliser R. Avery, Stephen Eubank, ChungChou Chang, Rachel R. Bailey, Diane K. Wagener, Donald S. Burke, Richard Platt and Susan

S. Huang, 2011, "Social network analysis of patient sharing among hospitals in Orange County, California". American Journal of Public Health, 101(4): 707-713.

Leenders, Roger T.A.J., 1997, “Longitudinal behaviour of network structure and actor attributes: Modelling interdependence of contagion and selection". In Patrick Doreian and Frans N. Stokman (Eds.) Evolution of social networks. Amsterdam: Gordon and Breach, pp. 165-184.

Lomi, Alessandro, Daniele Mascia, Duy Quang Vu, Francesca Pallotti, Guido Conaldi and Theodore J. Iwashyna, 2014, “Quality of care and interhospital collaboration. A study of patient transfers in Italy". Medical Care, 52(5): 407-414.

Lomi, Alessandro and Francesca Pallotti, 2012, "Relational collaboration among spatial multipoint competitors". Social Networks, 34(1): 101-11.

Lorraine, Francois and Harrison C. White, 1971, "Structural equivalence of individuals in social networks". Journal of Mathematical Sociology, 1: 49-80.

Lynk, William J., 2001, "One DRG, one price? The effect of patient condition on price variation within DRGs and across hospitals". International Journal of Health Care Finance and Economics, 1: 111-137.

McDonald, Michael L. and James D. Westphal, 2003, "Getting by with the advice of their friends: CEOs' advice networks and firms' strategic responses to poor performance". Administrative Science Quarterly, 48: 1-32.

Mizruchi, Mark S., 1989, "Similarity of political behavior among large American corporations". American Journal of Sociology, 95: 401-424.

Mizruchi, Mark S., 1993, "Cohesion, equivalence, and similarity of behavior: A theoretical and empirical assessment". Social Networks, 15: 275-307.

Mizruchi, Mark S. and Christopher Marquis, 2006, "Egocentric, sociocentric, or dyadic? Identifying the appropriate level of analysis in the study of organizational networks". Social Networks, 28: 187-208. 
Oliver, Christine, 1990, "Determinants of interorganizational relationships: Integration and future directions". The Academy of Management Review, 15(2): 241-265.

Owen-Smith, Jason and Walter W. Powell, 2004, "Knowledge networks as channels and conduits: The effects of spillovers in the Boston biotechnology community". Organization Science, 15(1): 5-21.

Podolny, Joel M., 1994. Market uncertainty and the social character of economic exchange. Administrative Science Quarterly, 39(3): 458-483.

Powell, Walter W., 1990, “Neither market nor hierarchy: Network forms of organization”. In B. Staw and L.L. Cummings (ed.) Research in organizational behavior. Greenwich, CT: JAI Press, pp. 295-336.

Powell, Walter W., Kenneth W. Koput and Laurel Smith-Doerr, 1996, "Interorganizational collaboration and the locus of innovation: Networks of learning in biotechnology". Administrative Science Quarterly, 41:116-45.

Powell, Walter W., Kenneth W. Koput, Laurel Smith-Doerr and Jason Owen-Smith, 1999, "Network position and firm performance: Organizational returns to collaboration in the biotechnology industry". In S.B. Andrews and D. Knoke (ed.) Networks in and around organizations, Vol. 16 of Research in the Sociology of Organizations. Greenwich, CT: JAI Press, pp. 129-159.

Provan, Keith G., Amy Fish and Joerg Sydow, 2007, "Interorganizational networks at the network level: A review of the empirical literature on whole networks". Journal of Management, 33: 479-516.

Provan, Keith G. and H. Brinton Milward, 1995, “A preliminary theory of interorganizational network effectiveness: A comparative study of four community mental health systems". Administrative Science Quarterly, 40: 1-33.

Provan, Keith G. and Juliann G. Sebastian, 1998, "Networks within networks: Service link overlap, organizational cliques, and network effectiveness”. Academy of Management Journal, 41(4): 453-463.

Rao, Hayagreeva, Gerald F. Davis and Ward, A., 2000, "Embeddedness, social identity and mobility: Why firms leave NASDAQ and join the New York Stock Exchange”. Administrative Science Quarterly, 45: 268-292.

Reagans, Ray and Bill McEvily, 2003, "Network structure and knowledge transfer: The effects of cohesion and range". Administrative Science Quarterly, 28: 240-267.

Rivera, Mark T., Sara B. Soderstrom and Brian Uzzi, 2010, "Dynamics of dyads in social networks: Assortative, relational, and proximity mechanisms”. Annual Review of Sociology, 36: 91-115. 
Rowley, Timothy J., Henrich R. Greve, Hayagreeva Rao, Joel A.C. Baum and Andrew V. Shipilov, 2005, "Time to break up: Social and instrumental antecedents of firm exits from exchange cliques". Academy of Management Journal, 48(3): 499-520.

Rowley, Timothy J., Joel A.C. Baum, Andrew V. Shipilov, Henrich R. Greve and Hayagreeva Rao, 2004, “Competing in groups". Managerial and Decision Economics, 25: 453-471.

Ruef, Martin and W. Richard Scott, 1998, "A multidimensional model of organizational legitimacy: Hospital survival in changing institutional environments". Administrative Science Quarterly, 43: 877-904.

Scott, W. Richard and John W. Meyer, 1983, “The organization of societal sectors”. In: John, W. Meyer and W. Richard Scott (Eds.), Organizational environments: Rituals and rationality. Sage, Newbury Park, CA, 129-153.

Sgourev, Stoyan V. and Ezra W. Zuckerman, 2011, "Breaking up is hard to do: Irrational overcommitment in an industry peer network". Rationality and Society, 23: 1-32.

Simon, Herbert A., 1962, "The architecture of complexity". Proceedings of the American Philosophical Society, 106(6): 467-482.

Slattery, Eoin and Gavin C. Harewood, 2012, "Specialty-specific admissions: a cost-effective intervention?”. Irish Journal of Medical Science, 181: 87-91.

Sohn, Min-Woong, 2002, “A relational approach to measuring competition among hospitals". Health Services Research, 37: 457-483.

Sohn, Min-Woong, 2001, "Distance and cosine measures of niche overlap". Social Networks, 23: 141-165.

Stuart, Toby E., 1988, "Network positions and propensities to collaborate. An investigation of strategic alliance formation in a high-technology industry”. Administrative Science Quarterly, 43: 668-698.

Stuart, Toby E., 2000, "Interorganizational alliances and the performance of firms: A study of growth and innovation rates in a high technology industry". Strategic Management Journal, 21: 791-811.

Szulanski, Gabriel, 1996, "Exploring internal stickiness: Impediments to the transfer of best practice within the firm”. Strategic Management Journal, 17: 27-43.

Tahari, Paul A., Butz David A., Dechert Ron and Lazar J. Greenfield, 2001, "How DRGs hurt academic health systems". Journal of the American College of Surgeons, 193: 1-8.

Uzzi, Brian, 1996, "The sources and consequences of embeddedness for the economic performance of organizations: The network effect". American Sociological Review, 61(4): 674-698. Uzzi, Brian, 1997, "Social structure and competition in interfirm networks: The paradox of embeddedness". Administrative Science Quarterly, 42: 35-67. 
Veinot, Tiffany C., Emily A. Bosk, K.P. Unnikrishnan and Theodore J. Iwashyna, 2012, "Revenue, relationships and routines: The social organization of acute myocardial infarction patient transfers in the United States”. Social Science \& Medicine, 75: 1800-1810.

Wasserman, Stanley and Katherine Faust, 1994, Social network analysis: Methods and applications. Cambridge: Cambridge University Press.

Westphal, James D. and Edward J. Zajac, 1997, "Defections from the inner circle: Social exchange, reciprocity, and the diffusion of board independence in U.S. corporations". Administrative Science Quarterly, 42: 161-183.

White, Harrison C., 1980, "A heteroskedasticity-consistent covariance matrix estimator and a direct test for heteroskedasticity". Econometrica, 48(4): 817-83.

White, Harrison C., Scott A. Boorman and Ronald L. Breiger, 1976, "Social structure from multiple networks. I. Blockmodels of roles and positions". The American Journal of Sociology, 81(4): 730-780.

Williamson, Oliver E., 1991, "Comparative economic organization: The analysis of discrete structural alternatives”. Administrative Science Quarterly, 36(2): 269-296.

Zaheer, Akbar and Geoffrey G. Bell, 2005, "Benefiting from network position: Firm capabilities, structural holes and performance”. Strategic Management Journal, 26(9): 809-26. 